\title{
The Digital Etiquette of the Kindergarten Teacher Pre- Service When Using Electronic Educational Platforms from the Point of View The Faculty Members
}

\author{
Prof. Randa Moustafa El-Deeb \\ Professor of Foundations of Child Education, Education Faculty, Tanta University, Egypt \\ randa.eldeeb@edu.tanta.edu.eg
}

\begin{abstract}
The aim of the Study was to try to determine the most important digital ethics for the kindergarten teacher before the service, which is represented in the digital etiquette when using electronic educational platforms from the point of view of the faculty members, and this is due to the increasing reliance on the use of digital technology as a means of communication in society in general and in the university in particular, This is in addition to what we live in under the "Covid 19" pandemic and what it has imposed on dealing and communicating in all fields. Providing the decision and those responsible for the educational process with basic educational information, number of (60) open questionnaires were distributed to faculty members specializing in "kindergarten" and "education technology" in different colleges and universities in the Arab Republic of Egypt. Electronic educational platforms from the point of view of faculty members at the university level, and this is for the benefit and advancement of them in dealing with colleagues, professors and all workers inside and outside the university.
\end{abstract}

Keywords: Digital etiquette, pre-service kindergarten teacher, electronic educational platforms, faculty members.

\section{Introduction}

Digital technology currently plays an important role in all activities as a result of rapid progress and the possibilities it provides in all fields. Despite these increasing effects of the use of digital technology on all individuals within society, the study of the ethics of the digital age, especially in the field of preparing the preservice kindergarten teacher, is still not Found; This student/teacher is the future teacher responsible for preparing and forming the digital children's generation. She must have the ethics of the digital age that she will instill in the future child. The child is not expected to develop positive values, morals and behaviors for himself, but rather learns them through his contact with the family and his kindergarten teacher. This requires more in-depth studies of these ethics and their impact on Egyptian society in general and on the kindergarten child in particular.

Education in the era of digital technology is one of the most advanced fields, and e-learning is one of the most important applications of digital technology in the field of science (Al-Baghdadi, 2020), as it is based on the use of its tools represented in electronic computers, networks, satellites, mobile phones and other tools and techniques that help in technological communication. (Bossis, 2020), which has become the main tool for interaction in the current digital age, especially at the university level. Homes were transformed into schools or lecture halls in one way or another. Thus, names such as "Zoom", "Classiera" and "Blackboard" became familiar to faculty members, students and their parents, who became acquainted with them more day by day, and the house became a major participant in the process Learning (AlDaoud, 2020).

She mentioned (Abdullah, 2013) many of the current problems of society are due to the fact that they are ethical problems, and their manifestations express a moral crisis resulting from a deficiency in the development of the moral aspect in the personality of its members. It also emphasized (Ali, 2018) the prominent role of the university in consolidating ethics, values and rules of behaviour among university youth, enabling them to understand how to use digital technologies in a 
safe, ethical and legal way to be good digital citizens. The results of the study (Abdullah, 2015) also emphasized the need to develop university youth awareness of digital respect and digital education.

There are many benefits of employing electronic educational platforms in education, which I mentioned (El-Ahwal, 2020), including: facilitating and developing the communication system between all those who deal with this platform, including teachers, students and parents, and parents can know how their children learn and monitor children during Being at home, crossplatform education increases students' effectiveness and helps develop the concept of continuing education and education outside the classroom. Facilitating teacher access to educational resources, teachers can benefit from communication with students and benefit from development based on the concept of feedback. Increase opportunities for collaborative learning and interaction between teachers and schools; To bring together resources and expertise, promote cooperation among students, and increase interaction between all these parties. (Zaki 2020) also emphasized that the student, through these platforms, has a greater ability to learn by himself and assess his educational level, in addition to the large number of references that help teachers choose attractive and renewable educational references and methods.

\section{Methodology:}

\section{Questions}

According to the results of studies and Study and what they have referred to, and as a result of the lack of studies on this subject with regard to its importance in the Arab world, especially in Egypt, where a similar study has not been conducted on this subject so far, the Researcher believes that conducting such a study has become an urgent need, so This study aimed to arrive at the rules of digital etiquette that are required to be taught to the kindergarten teacher before service when she uses electronic educational platforms from the point of view of the faculty members.

That is why the current Study came as an attempt to answer the following main question:

What digital etiquette is required for a kindergarten teacher to acquire before service when she uses electronic educational platforms from the point of view of faculty members?

The following questions are derived from this main question:

1- What is meant by digital etiquette?

2- What are the rules of digital etiquette that are required to be taught to the kindergarten teacher before the service when she uses electronic educational platforms from the point of view of the faculty members?

\section{Objectives}

The current Study aims to:

1- Defining digital etiquette.
2- Reaching the rules of digital etiquette required to be imparted to the kindergarten teacher before the service when she uses electronic educational platforms from the point of view of the faculty members.

\section{Importance}

Significance is shown by trying to Study:

1. In response to recent trends in the field of information and communication technology and its applications in the field of education.

2. Providing solutions and technical rules regarding the digital etiquette required to be imparted to the pre-service kindergarten teacher when she uses electronic educational platforms from the point of view of the faculty members due to the increasing use and dependence on them mainly in digital communication.

3. Presenting the rules of digital etiquette in the form of practical steps to be practiced on the ground and to reduce the challenges of emotional education in the digital age; This has been confirmed by some recent studies and Study of the chaos of electronic communication - intellectual invasion - violence and electronic bullying - electronic addiction - the deterioration of moral values - the diminishing role of educational institutions - the contradiction in receiving digital educational knowledge - cultural alienation.

4. Opening a new field for Researcher to conduct Study and studies in it.

\section{Previous Studies}

The first study: A study of Al-Ashry, Enas Farouk and El-Deeb, Randa Moustafa (2010) entitled "Etiquette of the Kindergarten Child and its Relationship to Some Variables". It aimed to measure the extent to which the art of etiquette exists in the kindergarten child, and what are the variables associated with it in order to be measured and ensure its existence, and the degree of this presence as there are no measures to measure etiquette in the kindergarten child; Within the limits of the Studyers' knowledge.

The second study: A study of Asaker's, Ayman Ibrahim El-Desouky Ibrahim (2013), entitled "Digital technology and its social implications: a field study in the city of Cairo" and aimed at determining the social repercussions of digital technology on students of Ain Shams University.

The third study: the study of Al-Rashed, Madawi Abdel-Rahman (2018) entitled "The degree of kindergarten teacher owning digital learning and its attitude towards its use." The study aimed to know the attitudes of kindergarten teachers towards the use of digital learning and the degree of possession of digital learning skills.

The fourth study: A study of Ali, Iman Fathy Ibrahim (2018) entitled "Using professional practice techniques for working with groups and developing university youth awareness of digital citizenship." digital, and trying to 
prepare them to face the repercussions of the scientific and technological revolution.

The fifth study: the study of Saleh, Abul-Fotouh AbulFotouh Muhammad (2019), entitled "The Impact of Technological Development on the Exercise of Rights and Public Freedoms". It aimed to find some solutions to the problem of misuse of technical or technological development in general, and mobile phones in particular.

The Sixth study: A study by Badawi, Mahmoud Fawzi Ahmed (2019), entitled "The Challenges of Emotional Education in the Digital Age from the Point of View of Some Faculty Members in Faculties of Education". It aimed to reach the challenges of emotional education in the digital age.

The seventh Study: A Study by Al-Senussi, Hala Abdel-Qader Saeed (2019), entitled "The Roles of EPlatforms and Social Networks as Participatory Communicative Learning Environments in E-Learning in the Light of the Student's Experience". It aimed to compare the roles of E-platforms and social networks as communicative and participatory learning environments in university e-learning, as well as investigating the significance of the differences between the use of educational platforms according to the type of platform (open - closed), and the significance of the differences between the use of educational platforms at different academic level (sixth -VIII).

The Eighth study: A Study by El-Ahwal, Marwa Nabil (2020), entitled "Effect of Micro-Teaching Method Supported by E-Learning Platforms in Enriching Preservice Mathematics Teachers' Teaching Practice s And Improve Self-efficacy". It aimed to explore the effect of micro-teaching method supported by e-learning platforms in enriching the teaching practice of pre-service mathematics teacher students, and to explore the effect of micro-teaching method supported by e-learning platforms in improving the self-efficacy of mathematics teachers for pre-service students.

\section{Design}

To answer the first question of the Study, which is what is meant by digital etiquette?

It is difficult to claim that etiquette is found in books, and whoever wants to learn it should read these books; Just reading is not enough to learn it. It is basically a practice and a long acquired experience since childhood, before it became rules of memorization and theories to be applied (Kojk 2004). Therefore, it was necessary to establish some ethics or moral values or what is known as digital etiquette for the kindergarten teacher before the service through her entry or presence on the various electronic educational platforms in light of the "Covid 19" pandemic (El-Deeb, 2021).

Digital etiquette is something that we acquire and maintain through practice, and teaching and imparting it to students/teachers is not difficult when the matter is taken seriously; It is wonderful to see them behave ethically from the stage of their preparation (El-Deeb, 2016) until their graduation from university. The digital etiquette of the kindergarten teacher before service is procedurally meant that it is the acquisition of the student / teacher (kindergarten major) during the period of preparation of the digital knowledge and ethics related to the correct use of digital technology and the acquisition of various skills that help her to make optimal use of this technology and support effective communication in a positive way, and avoiding the negatives of use The bad technology of technology and its applications, as well as qualifying it to be an effective and influential digital citizenship while preserving at the same time the values, customs and culture of the community, and practicing digital ethics inside and outside the university.

And " Murno, Leaf " (2004) mentions that there is a certain fact of teaching a child etiquette, which is that children acquire all the behaviors and morals enjoyed by their parents and teachers; They learn from them how to behave in every situation and what to do in each case (Al-Ashry and El-Deeb 2010), so the kindergarten teacher was chosen during her preparation period inside Curriculum the university to teach her the rules of digital etiquette.

The Researcher relied on the descriptive approach in order to determine the most important rules of digital etiquette to be taught to the kindergarten teacher before service when she uses electronic educational platforms from the point of view of the faculty members.

\section{Study tool and application}

In order to achieve the objectives of the Study and to answer the second question of the Study questions, an open questionnaire was made with the following question:

What are the rules of digital etiquette that must be taught to a kindergarten teacher before service when using electronic educational platforms from the point of view of the faculty members in their preparation institutions, with their order from highest to least in importance?

A number of (60) questionnaires were distributed, and the number, after reviewing and excluding the invalid, reached (54) questionnaires.

\section{Results \& Discussion}

In light of the objectives of the Study, its questions, and the results of unpacking the Study tool used, the most important rules of digital etiquette that are required to be taught to the kindergarten teacher before service when using electronic educational platforms and others were reached from the point of view of the faculty members in their preparation institutions.

Which is next:

1- That the student/teacher have a real desire to be a digital teacher after her graduation and have digital and technological culture and to deliver information in a successful and effective way to the kindergarten child. Students do well and use e-learning technology more widely.

2- Not to use useless websites and know the appropriate websites for learning and Study. 
3- Maintaining their safety online, including the information they must share and with whom they are shared. This was confirmed by a study (Asaker, 2013) that digital technology has many defects, including spying and mistrust in the performance and information provided through it through this technology.

4- A real awareness that you should refrain from sharing information such as female colleagues' names, home addresses, behavior information, or any other personal details; Because leaking this information may push it to fall into the hands of fraudsters and harassers and expose it to sexual exploitation, and this is confirmed by (Watch, 2020). It also exposes them to blackmail people through this information. This is what was reached (Asaker, 2013) in his study of the social repercussions of digital technology.

5- To enter her real name and not to use pseudonyms, and not to enter false identities for amusement or ridicule. This was confirmed by the study (Ali, 2018) of developing university youth awareness of digital citizenship.

6- Early entry before the lecturer enters the e-learning platform, while adhering to the controls for attendance and direct interaction with the lecturer.

7- $\quad$ Sitting during the lecture in a place away from the noise and disturbance in the house.

8- Close the camera and the sound Unmute, and they are not opened unless requested by the lecturer.

9- When asking a question, the Raise Hand must be raised, and the question must not be asked directly, except after obtaining permission from the official.

10- Availability of a paper and a pen next to the student to take notes on time, and not to complain and complain about the assignments and duties entrusted to her and her work and not to delay them, and send them on time. The study of (El-Ahwal, 2020) confirmed the contribution of e-learning platforms to increasing opportunities for cooperative education and interaction between members faculty and students; To bring together resources and expertise, promote cooperation among students, and increase interaction between all these parties.

11- Not to talk to someone you do not know, do not write comments, do not offend anyone, and publish useful images on e-learning platforms and social networking sites (Watfa, 2021).

12- Staying away from the practice of electronic bullying in all its forms and respecting the ideas and beliefs of others, and this is the findings of the study (Badawi, 2019) of the challenges of emotional education in the digital age, which are represented in the chaos of electronic communication - violence and electronic bullying.

13- Not to offend or harm any person, no matter how big the difference with him is (spying, sending viruses, distributing immoral files to others). This is what the study (Saleh, 2019) concluded regarding the impact of misuse of technical or technological development in general, and social media, computers, and mobile phones in particular.

14- Observing the etiquette of dialogue and the etiquette of behavior in electronic communication (Al-Sharq Newspaper, 2007). The results of the study (Asaker, 2013) indicated that this technology is commonly used by humans without the influence of factors such as the level of education or housing ... etc.

15- A sense of responsibility and the responsible use of the international information network by investigating honesty, reliability and honesty in requesting data and information. This was confirmed by the recommendations of the study (Al-Rashed 2018) to enrich the teacher preparation programs with courses related to e-learning and the use of computers and the Internet in learning and teaching.

\section{Recommendation}

Since technological communication represents a major tool for interaction in the digital age in general and especially in the university in particular, the current Study presented a set of digital etiquette rules that must be taught to the kindergarten teacher before service when using electronic educational platforms as an attempt to treat some of the problems and challenges that currently exist from the chaos of electronic communication Addiction, violence and cyberbullying - Cultural and psychological alienation - Reducing the role of some educational institutions - Lack of correct educational digital knowledge information.

\section{This Study recommends the following:}

- 1. Pre-service training of kindergarten teachers on the rules of digital etiquette that were reached in the current Study when using electronic educational platforms, to become a digital student and teacher, and this is achieved by training them for themselves on those ethics through building and implementing habits, then persevering with commitment and focus on them.

-2. Awareness of kindergarten teachers before service about the importance of digital technology and its impact on social relations, in particular the importance of following the ethics of dealing with the Internet, as it is one of the technological developments, especially educational ones, in obtaining various scientific information.

- 3. Allocating a special course for everything related to digital etiquette taught to first-year students in all divisions within the various colleges and universities.

- 4. Increased interest in using electronic educational platforms in education at its various stages, in 
order to reduce the educational problems that the educational process suffers from.

-5. Holding training courses for kindergarten teachers to keep up with everything new and modern in the field of digitization and digital citizenship.

-6. Conducting training courses and intensive introductory workshops on the ethics and etiquette of digital technology and its impact on relations to train faculty members and the university's supporting staff to serve their scientific career.

-7. Conducting training courses and intensive introductory workshops for parents of children and students in universities on the benefits and methods of using electronic educational platforms.

- 8. Every college and university has a YouTube channel that uploads files on digital etiquette and everything new in the field of digital technology by providing simple educational videos that explain to students the method of communication and digital etiquette to be used when entering electronic and other educational platforms.

\section{Suggestions}

The current Study suggests:

1- Conducting similar studies in the field of digital etiquette for faculty members when using electronic educational platforms within educational institutions, whether schools or universities.

2- Conducting similar studies in the field of digital etiquette for school students in different educational stages to provide them with the rules of digital etiquette and digital citizenship and other challenges of the digital age.

\section{References}

[1] Abdullah, Hamdi (2015). General practice of social work and the development of university youth awareness of digital citizenship: a study applied to university youth in Qena Governorate, Journal of Studies in Social Work, issue (39), part (6), Faculty of Social Work, Helwan University, October, 230301.

[2] Abdullah, Iman (2013). The effectiveness of a proposed program based on the digital image in teaching religious education to develop some moral values among primary school students, unpublished master's thesis, Department of Curricula and Teaching Methods, College of Education in Hurghada, South Valley University.

[3] Al Sharq Newspaper (2007). Etiquette for electronic conversation and the use of messenger, issue (102), October 28.

[4] Al-Ashry, Enas Farouk and Al-Deeb, Randa (2010). Etiquette of the kindergarten child and its relationship to some variables, Journal of the College of Education, No. 41, Tanta University.

[5] Al-Baghdadi, Fatima (2020). Transformations of Education in the Time of Corona, Al-Karafa, December, http://bitly.ws/aKzc

[6] Ali, Iman Fathy (2018). Using professional practice techniques for working with groups and developing university youth awareness of digital citizenship, unpublished $\mathrm{PhD}$ thesis, Faculty of Social Work, Assiut University.

[7] Al-Rashed, Madawi (2018). The Kindergarten Teacher's Degree of Owning Digital Learning and Her Attitude Towards Using It, The Journal of the Islamic University for Educational and Psychological Studies, Volume (26), No. (3), The Islamic University of Gaza, May, 407-432.

[8] Asaker, Ayman (2013). Digital technology and its social implications: a field study in the city of Cairo, an unpublished master's thesis, Department of Environmental Humanities, Institute of Environmental Studies and Research, Ain Shams University.

[9] Badawi, M Ahmed (2019). Challenges of emotional education in the digital age from the point of view of some faculty members in the faculties of education. The Educational Journal of the Faculty of Education in Sohag, Issue (60), April, 218-316.

[10] Boqhous, Khaled (2020). The future of education in light and after the Corona pandemic (1), Gulf News, May 5.

[11] Bossis, Wassila (2020). The Strategy of Closing Educational Institutions to Limit the Spread of the Covid-19 Virus" The Challenge of Digitization and the Bet of Distance Education, Journal of Social Empowerment, Issue (2), Volume (2), September, 20-33.

[12] El-ahwal, M. (2020). Effect of Micro-Teaching Method Supported by E-Learning Platforms in Enriching Pre-service Mathematics Teachers' Teaching Practice $\mathrm{s}$ and Improve Self-efficacy. International Journal of Instructional Technology and Educational Studies, 1(3), 18-31. doi: 10.21608/ihites.2020.43173.1036

[13] El-Deeb, Randa (2016). Moral Education for the Child, Dar Al-Kitab Al-Hadith, Cairo.

[14] El-Deeb, Randa (2021). The Art of Crisis Management, the second discussion session entitled The Role of Civil Society in Facing Corona (Govid 19 Pandemic), held on January 16/17, 2021, the Arab African Forum for Training and Development, via Zoom technology.Impact analysis. Policy responses and recommendations. April 9.2020.

[15] Jess, Edwards (2020). The impact of COVID-19 on children's lives. Save the Children International . Protect a Generation: The impact of COVID-19 on children' s Lives.19/9/2020 I Re-source Centre ( savethechildren.net)

[16] Kojk, Kawthar Hussain (2004). Teaching and learning values and morals begins in kindergarten, 
the Fourth Scientific Conference, "Education and Moral Education for a New Millennium", September 8-9.

[17] Leonard ,Melissa (2009). Manners and etiquette [Available online-http://www. A-to- $\mathrm{Z}$ of.com/school- etiquette.html Date: Fri, 6 Jul 2009 11:06./:54 EDT,

[18] Manners, Murno L. (2004). Can Be Fun, Universal New York.

[19] Saleh, Muhammad (2019). The impact of technological development on the exercise of rights and public freedoms: an unpublished $\mathrm{PhD}$ thesis, Department of Public Law, Faculty of Law, Ain Shams University.

[20] Sanusi, Hala (2019). The Roles of E-Platforms and Social Networks as Participatory Communicative Learning Environments in E-Learning in the Light of the Student's Experience, Education Journal, No. (181), Part (3), College of Education, University of Al-Azhar, January, 57-89.

[21] UNESCO IESALC .Report(2020).COVID-19 and higher education: today and tomorrow

[22] UNESCO (2020). The impact of Covid-19 on the cost of achieving SDG 4.GEM Report Policy

[23] Von, Samantha (2009).Manners and Etiquette for Children ,

[24] Watch, Human right (2020) . COVID-19 and children 's Rights.April 9.2020. COVID-19 and Children's Rights. Pdf (re-lief-web.int).accessed on 19/12/2020.

[25] Watfa, Ali Asaad (2021). The Problems and Challenges of E-Learning in the Light of the Corona Pandemic (A Sociological Reading in the Dialectics of Interaction and Influence), Issue (7), Istikab Publications Series, Center for Gulf and Arabian Peninsula Studies, Kuwait University.

[26] WHO(2020).Coronavirus disease (COVID- 19) Pandemic.World health Organization.https://www.who.int/emergencies/disea ses/novel-coronavirus-2019.

[27] Zaki, Walid (2020). Will Corona succeed in developing online education? Aswat, April 4, 2020, aMHP/ws.bitly://http, accessed on 12/11/2020.

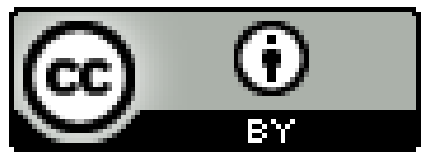

